\title{
25 Research Square \\ Design and psychometric properties of BAtSS: A new tool to assess human attitudes towards bats.
}

\section{Beatriz Pérez}

Universidad de La Frontera https://orcid.org/0000-0003-0180-808X

\section{Boris Álvarez}

Universidad Católica de Temuco https://orcid.org/0000-0002-9725-938X

\section{Alex Boso}

Universidad de La Frontera https://orcid.org/0000-0002-0313-8238

Fulgencio Lisón ( $\nabla$ flison@udec.cl)

Universidad de Concepción https://orcid.org/0000-0003-1481-3750

\section{Research Article}

Keywords: Chiroptera, conservation, human-wildlife conflict, psychometric properties

Posted Date: August 28th, 2020

DOI: https://doi.org/10.21203/rs.3.rs-66342/v1

License: (c) (i) This work is licensed under a Creative Commons Attribution 4.0 International License. Read Full License

Version of Record: A version of this preprint was published at Animals on January 20th, 2021. See the published version at https://doi.org/10.3390/ani11020244. 


\section{Abstract}

Despite the benefits that bats offer the ecosystem, these animals are feared due to mythological beliefs and their association with dirt and disease. The COVID-19 pandemic has aggravated this situation, exacerbating the already habitual attacks on these creatures. Today there is an urgent need to address the human-bat conflict in order to develop conservation policies. Understanding peoples' attitudes towards bats is a key part of this process. The object of this study was to design the Bats Attitudes Standard Scale (BAtSS) and analyse its psychometric properties. We developed an initial version of the scale in which we established the content validity; we analysed the items and structure in a pilot sample. In the next phase, we analysed psychometric properties in a sample of 1639 Chilean people. The final BAtSS consists of 34 Likert-type items configured in an oblique-hierarchical structure of 4 factors (Scientistic, Positivistic, Negativistic and Myths) and 3 facets (Negativistic-Emotional, Negativistic-Behavioural and Negativistic-Cognitive). It presents adequate internal consistency and the analysis of concurrent validity confirms the capacity of the scale to discriminate between groups. Women and participants with a lower level of education are more Negativistic and less Positivistic. People with a higher level of education have a less mythological view of bats. We also analysed the items which would be more/less difficult to change under the assumptions of Item Response Theory (IRT). Finally, BAtSS is a robust tool to assess the human attitudes and could help to understand and solve human-wildlife conflicts and therefore, improving the conservation actions

\section{Introduction}

In late March 2020, during the coronavirus pandemic, a group of villagers from Culden, Peru, used burning torches to attack a colony of 500 bats which lived in a cave. Alerted by the rumour that COVID-19 started when someone in China ate bat soup, the residents corralled the animals and burnt them, killing 300 specimens. The majority of the bats in the Culden colony were of the genus Myotis, insectivores which are inoffensive to human beings. Unfortunately, this is not the first time that bats have come under the spotlight when a virus affects humans. Historically, despite the many benefits they provide to the planet, bats have been subject to several stigmas, misunderstandings and folk beliefs (Aziz et al., 2017; Barnes, 2013; Bhattacharjee et al., 2018; Castilla et al., 2020; Musila et al., 2018; Prokop et al., 2009; Prokop \& Tunnicliffe, 2008; Rego et al., 2015; Reid, 2016; Shapiro et al., 2020).

Many features make bats singular and, in some ways, surprising animals. Few people know that bats (Mammalia: Chiroptera) are among the most diverse orders of mammals, with more than 1300 species(Upham et al., 2019). Some of them have developed an immune system prepared to resist different types of virus, including coronaviruses. Understanding their biological characteristics could help the scientific community to find key mechanisms to control COVID-19 or other viruses that can affect humans. Bats provide important ecosystem services such as pollination, seed dispersion and pest suppression (Kunz et al., 2011). Almost all species of bats therefore enjoy high levels of institutional protection. Nevertheless, society does not recognise the benefits of bats for the ecosystem (LópezBaucells et al., 2018; Mahmood-ul-Hassan et al., 2011; Santos et al., 2019; Tanalgo et al., 2016). Worse still, bats have often had to deal with the consequences of human misconceptions about them, and our irrational fears (Kingston, 2016; Knight, 2008). In recent decades they have become highly threatened due to anthropic disturbances (habitat loss, destruction of refuges and alteration of trophic structure). The "disease avoidance" hypothesis indicates that we fear bats because they disgust us; we associate them with dirt and the propagation of disease (Lim \& Wilson, 2019; López-Baucells et al., 2018; Moran et al., 2015; Rego et al., 2015; Reid, 2016; Tanalgo et al., 2016). This situation has been aggravated as a consequence of the Covid-19 pandemic, during which they have been a focus of media attention. 
Policies for conservation management of species which are the subject of wildlife-human conflicts therefore require investigation into attitudes towards these animals (Rego et al., 2015). Nevertheless, there is little literature which has explored people's attitudes towards bats, and what there is suffers from a lack of consensus in the definition and operationalisation of the construct.

\subsection{Measuring attitudes towards bats}

Some works approach this construct through semi-structured interviews and/or open questions, or design test questions expressly for the investigation in hand with little psychometric analysis (Aziz et al., 2017; Bhattacharjee et al., 2018; Castilla et al., 2020; Gbogbo \& Kyei, 2017; Moran et al., 2015; Rego et al., 2015; Shapiro et al., 2020). Other authors have developed specific scales, including analysis of content validity and internal consistency, mostly using Cronbach's alpha coefficient and/or principal component analysis. All offer information on group comparisons based on variables like gender, age or level of education, reflecting the ability of the scales to discriminate between individuals (Barnes, 2013; Fagan et al., 2018; Musila et al., 2018; Prokop et al., 2009; Prokop \& Tunnicliffe, 2008).

Kross et al. (2018) designed a scale on the perception of three types of animal (one per factor): bats, birds and birds of prey. Fagan et al. (2018) measured attitudes towards bats in a sample of 420 visitors to a natural park in USA, with a one-dimensional scale formed of four statements on hypothetical encounters with bats in buildings. The other quantitative instruments found in the literature all follow the same line, based on the typology of nine basic attitudes towards wildlife and its natural habitats developed by (Kellert, 1984, 1976): Naturalistic, Ecologistic, Humanistic, Moralistic, Scientistic, Aesthetic, Utilitarian, Dominionistic and Negativistic. (Kellert, 1980) developed sub-scales for each of these attitudes, except for Aesthetic.

Prokop et al. (2009) selected the dimensions Negativistic, Scientistic and Ecologistic from Kellert (1980) to evaluate attitudes specifically towards bats. They also added measurement of the dimensions of Myths and Knowledge, based on their importance in the scientific literature for understanding human behaviour towards these animals. They developed the Bat Attitude Questionnaire (BAQ), a Likert-type scale with 5 response alternatives, with a sample of 263 university students in Slovakia. The scale consisted of these 5 dimensions, although the Myths scale did not present adequate levels of internal consistency. Prokop and Tunnicliffe (2008) describe the construction of the same measure (BAQ) with a sample of 196 Slovak students aged between 10 and 16 years. They obtained a final instrument of 26 items, composed of three dimensions: Eco-Scientistic, Negativistic and Naturalistic. However, they did not consider Myths and Knowledge about bats as dimensions of the scale, but evaluated them as independent measurements.

Musila et al. (2018) used a version of Prokop et al.'s questionnaire (2009) adapted to their study sample of 294 Kenyans. The final scale of 19 items evaluated the dimensions Scientistic, Negativistic, Myths and Ecologistic. The dimension of Knowledge did not produce adequate indicators of reliability, so it was discarded from the instrument and considered as an independent measurement. (Barnes, 2013) developed the Battitude Questionnaire, a 47-item Likert-type scale, with 310 students in Rodrigues Island, Mauritius, based on the information collected in different focus groups and on other scales, BAQ between them. Factorial analysis produced 6 components, two of which coincided with the theoretical dimensions Eco-Scientistic and Negativistic. The author considered these and discarded the rest. He likewise included measurement of myths and knowledge in his study for understanding attitudes towards bats.

Despite the efforts of researchers to create an operative measurement scale with evidence of validity and reliability, a different or modified version is used in each study and therefore the results of each work are based on a different 
conceptual model of attitudes towards bats. The consequence is a limitation on the scope of the conclusions: we need an instrument which will remain constant between studies in order to obtain comparable results (Smith, 2005). Rigorous analysis in the construction of the scales and at the psychometric level could help us to solve this limitation (Hefetz \& Liberman, 2017; International Test Commission, 2017; Martínez-Arias et al., 2014; Muñiz \& FonsecaPedrero, 2019; Rodriguez et al., 2016).

In view of the above, the object of this study was to construct a scale of attitudes towards bats with evidence of reliability and validity in a Chilean community sample. To do this we analysed the factorial structure and the internal and concurrent validity of the content, and estimated the internal consistency. We also identified which attitudes are easiest and most difficult to modify for each dimension.

\section{Materials And Methods}

The construct - attitudes towards bats - is defined as relatively stable evaluations of bats, either positive or negative, at the cognitive, affective or behavioural level (Briñol et al., 2007). In view of their importance in the literature, we selected four of Kellert's nine attitude types $(1980,1984)$ for the theoretical definition of the dimensions of the instrument: (1) Scientistic - "primary interest in the physical attributes and biological functioning" of bats (Kellert, 1984); (2) Ecologistic - primary concern for bats and their natural habitats (Kellert, 1984); (3) Utilitarian "primary concern for the practical and material value" of bats and their animal habitat (Kellert, 1984); (4) Negativistic - "primary orientation an active avoidance of [bats] due to dislike or fear" (Kellert, 1984). We also included a fifth component: (5) Myths, defined as people's beliefs, legends or non-scientific knowledge about bats, based on the interest shown by researchers in the literature (Musila et al., 2018; Prokop et al., 2009; Prokop \& Tunnicliffe, 2008).

Following the recommendations for the cultural adaptation and validation of questionnaires, and for test construction (International Test Commission, 2017; Muñiz \& Fonseca-Pedrero, 2019), we carried out a retrotranslation process of the items of the existing questionnaires (Barnes, 2013; Kross et al., 2018; Musila et al., 2018; Prokop et al., 2009; Prokop \& Tunnicliffe, 2008). We selected the most appropriate for the Chilean cultural context and designed others. Some required modification as part of the process of linguistic and cultural adaptation. We finally obtained an initial version of 53 items: 12 for the Scientistic dimension, 18 for the Negativistic, 12 for the Ecologistic, 5 for the Utilitarian and 6 more for the dimension of Myths.

The instrument was subjected to the judgement of experts to obtain evidence of content validity. A table containing the definitions of the dimensions and the list of the 53 items, categorised according to the theoretical dimension of appropriateness, was given to 10 judges who were experts in the areas of ecology and conservation, sociology, psychology and attitude measurement. The judges had to answer the following questions: "Do you believe that this item is suitable for measuring the dimension indicated?" and "Do you believe that any important item or concept is missing to represent this dimension completely?"In the case of disagreement, they were asked to make a recommendation. After analysis of the answers, and obtaining agreement between the judges by group discussion, the wording of some items was modified and two of the Negativistic dimensions were eliminated as redundant.

A scale of 51 items was subjected to a pilot study with a sample of 67 university students. The researchers went to the classrooms to ask students to participate. Those who agreed to participate on a voluntary, confidential basis replied in situ to the questionnaire, which had been distributed previously online. Subsequently they commented to the researchers on the difficulties which arose. Several items were discarded on account of their low discriminative capacity and contribution to the consistency of the scale. Thirty-three of the 51 items were retained. These were subjected to EFA with varimax rotation and principal component extraction. The resulting 5-dimension factorial 
structure did not agree exactly with the theoretical structure: (1) the Scientistic dimension was the most consistent; (2) a second dimension emerged which we called Positivistic, combining the items that correspond to the theoretical dimensions Ecologistic and Utilitarian; and finally, the Negativistic theoretical dimension was divided into three, according to the attitude definition structure: (3) Negativistic-Emotional; (4) Negativistic-Behavioural, and (5) Negativistic-Cognitive. The dimension of Myths was eliminated. Nevertheless, considering the theoretical interest of this dimension, and the fact that the low internal consistency might have been influenced by the small sample size, it was kept for the following phase of this study. Finally, a preliminary scale of 39 items passed to the next phase of the work.

\subsection{Participants}

A sample of 2189 participants was collected by non-probabilistic convenience sampling. After eliminating the incomplete questionnaires and those which did not meet the selection criteria, a final sample of 1639 participants was obtained, all Chilean nationals' resident in the country, aged over 18 years and not related with professional or productive agriculture. Table 1 shows the descriptive data.

\section{Table 1}

Sociodemographic characteristics of the participants 


\begin{tabular}{|ll|}
\hline Variables & $\mathrm{n}(\%)$ \\
\hline Gender & $747(45.6)$ \\
\hline Male & $887(54.1)$ \\
\hline Female & $5(0.3)$ \\
\hline Other & \\
\hline Age & $1194(72.8)$ \\
\hline$\leq 29$ & $402(24.5)$ \\
\hline $30-59$ & $43(2.6)$ \\
\hline$\geq 60$ & $863(52.7)$ \\
\hline Level of studies & $532(32.5)$ \\
\hline Undergraduate & $244(14.9)$ \\
\hline University or professional technician & \\
\hline Postgraduate & $630(38.4)$ \\
\hline Religion & $685(41.8)$ \\
\hline Christians & $498(30.4)$ \\
\hline Other religions & \\
\hline Atheist & \\
\hline None & \\
\hline Have you seen a bat in person? & \\
\hline Yes & \\
\hline No & \\
\hline
\end{tabular}

\subsection{Measurements}

Sociodemographic questionnaire. The instrument included a short section with sociodemographic questions for sample characterisation, with questions such as age, gender, educational level, area of study, nationality and religion.

Bats Attitudes Standard Scale (BAtSS) - preliminary version. Scale of 39 items with 5 response options: (1) Totally disagree; (2) Disagree; (3) Neither agree nor disagree; (4) Agree; (5) Totally agree. It was proposed that a theoretical structure existed of the 6 dimensions defined above: Scientistic (7 items); Positivistic (11 items, a combination of dimensions theorised as Biological and Utilitarian: primary concern for bats, their natural habitats and their practical and material value); Negativistic-Emotional (4 items); Negativistic-Behavioural (4 items); Negativistic-Cognitive (7 items); and, Myths (6 items).

\subsection{Procedure}

An online survey was conducted from August to November 2019, using an electronic survey tool, SurveyMonkey (www.surveymonkey.com). There was substantial dissemination due to the link to the survey being broadly shared 
on social media via Twitter, Facebook, Instagram, Linkedin, Whatsapp, email, and through other channels. All the participants gave their voluntary consent to participate in the study. The surveys were anonymous and the researchers never collected the names of the participants in the survey or contacted them directly. The time taken to complete the survey was approximately 15-20 minutes.

\subsection{Data analysis}

The sample was divided into two parts at random: the first group consisted of 820 participants, and the second of 819. The first sample was used to analyse the discriminative capacity of the items by the corrected item-total correlation, the normality of the scores by the Kolmogorov-Smirnov (K-S) test, and the levels of kurtosis and asymmetry. We also explored the inter-item correlation per dimension by Pearson's correlation, to detect extreme levels of correlation. Finally, once the relevance of the data for factorial analysis had been established by Bartlett's index and the Kaiser-Meyer-Olkin (KMO) test, this first sample was subjected to EFA using the Unweighted Least Squares extraction method and Oblique Oblimin Rotation.

The 6-factor structure obtained in the first group was contrasted in the second. The analytic strategy used was Confirmatory Factorial Analysis (CFA), considering the Robust Unweighted Least Squares (ULSMV) estimator on a polychoric matrix, due to the ordinal nature of the data. In order to determine whether this factorial structure corresponded to a correlational or hierarchical model, we explored the fit of an oblique 6-factor model $\left(\mathrm{M}_{1}\right)$ and a second-order hierarchical model $\left(\mathrm{M}_{2}\right)$ (Sánchez-Oliva et al., 2017). In response to the theoretical relation between the Negativistic-Emotional, Negativistic-Behavioural and Negativistic-Cognitive factors, we explored an oblique solution which we called the hierarchical-oblique model $\left(\mathrm{M}_{3}\right)$, and a hierarchical solution which we called the third order hierarchical model $\left(M_{4}\right)$. In both $M_{3}$ and $M_{4}$ we included a fourth factor that we called Negativistic, consisting of three facets: Negativistic-Emotional, Negativistic-Behavioural and Negativistic-Cognitive. In $\mathrm{M}_{3}$ this factor correlated with the Scientistic, Positivistic and Myths factors, while in $\mathrm{M}_{4}$ the four factors present a higher order factor (See Figure 1).

Finally, we included analysis of the structure of this instrument as a Bifactor model (see Figure 1), based on the model with best fit to the 4 options named above $\left(\mathrm{M}_{5}\right)$ (Rodriguez et al., 2016; Sánchez-Oliva et al., 2017). This model explores the coexistence of a general factor that explains common covariance between all the variables observed, and the factors made up of the items with a higher shared variance. Fitting a Bifactor model enabled us to determine the existence of a sufficiently strong general factor to justify a global score, as well as scores for each individual factor (Reise, 2012; Rodriguez et al., 2016).

The fit of the models was assessed by the RMSEA, CFI and TLI fit indices. CFI and TLI $\geq .95$ and RMSEA $<.05$ was considered a good fit; and CFI and TLI $\geq .90$ and RMSEA <. 08 acceptable (Kline, 2016). Furthermore, to assess to what degree the data could be considered an essentially one-dimensional structure in M5, the OmegaH (Omega Hierarchical) coefficient, the PUC (Percent of Uncontaminated Correlations) and the ECV (Explained Common Variance) were used. OmegaH values from .80 are recommended for the total scores to be considered essentially one-dimensional (Reise et al., 2013). ECV and PUC values higher than .70 indicate a slight relative bias when the scale is considered essentially one-dimensional (Rodriguez et al., 2016).

Below we report the correlation between the factors in the scale. Suspicions of multicollinearity were discarded with tolerance values above .1, and Variance Inflation Factor (VIF) below 10. The reliability of the scale in both the first and second sample was calculated by Ordinal Alpha and McDonald's Omega, which are best suited to ordinal data. The fitted values must be higher than .70 (Rodriguez et al., 2016). Finally, with a random sample of 1000 participants we analysed the data under the assumptions of Item Response Theory (IRT) and took the Samejima Graduated 
Response Model (Samejima, 1968). This is a particular case of the two-parameter logistic model. It indicates the capacity of each item to discriminate the estimated score of each participant in the factor (Parameter a): the higher the score in this parameter, the greater the discriminative capacity. It also indicates the probability of selecting a specific response category or a higher category for a given level of the measurement variable, i.e. for each response option of each item (Parameter b). According to the cumulative process defined by Samejima (1968), the difference $b_{4}-b_{1}$ is indicative of the difficulty/ease of changing from one extreme to the other in the measurement levels, i.e. to change from totally disagree to totally agree or vice-versa: the higher the score, the greater the difficulty.

To analyse the concurrent validity, we used the complete database $(\mathrm{N}=1639)$. The $\mathrm{K}-\mathrm{S}$ test was used to show that there was no normal distribution of the univariate data for the total score in the scale factors. Levene's test showed that a few cases did not comply with the assumption of homoscedasticity. Nevertheless, this is no hindrance to method selection when the sample size is large (Fagerland, 2012). We selected Student's t test to compare the means of two groups, and Hedges' $g$ to calculate the size of the correction effect for groups of different sizes. One factor ANOVA was used to compare the means of more than two groups, with Scheffe's contrast method adapted for groups of different sizes, and Cohen's d for ANOVA with multiple groups. In both cases, values up to .2 report a small effect, from .2 to .4 an intermediate effect, and .4 or higher a large effect (Cohen, 1988). The following softwares were used for this study: SPSS 24.0, FACTOR 10.9, Excel, Mplus 7.11 and IRTPRO.

\section{Results}

\subsection{Preliminary analyses}

None of the items has a normal distribution. Of the 39 items, five presented an asymmetry index lower than 2, and of these five, two had a kurtosis index higher than 7 (Table 2). Nonetheless, the items considered uninformative because they did not discriminate between subjects were those with a frequency of $95 \%$ or higher in one response option. The five items mentioned presented percentages between 75.1 and $86.7 \%$ in one response option, indicative of a low but not nil discriminative power. It was therefore decided to retain them as part of the instrument.

\section{Table 2}

Descriptive data and item-total correlation corrected by dimension. Items of the definitive BAtSS in group 1 sample $(N=820)$ 


\begin{tabular}{|c|c|c|c|c|c|c|c|c|c|c|c|}
\hline Item & Mean & SD & Skewness & Kurtois & ITC & Item & Mean & SD & Skewness & Kurtosis & ITC \\
\hline \multicolumn{6}{|c|}{ Scientistic } & \multicolumn{6}{|c|}{ Negativistic-Behavioural } \\
\hline 1 & 4.01 & .854 & -.760 & .763 & .668 & 31 & 1.38 & .772 & 2.284 & 5.444 & .760 \\
\hline 2 & 3.33 & 1.032 & -.182 & -.397 & .710 & 32 & 1.31 & .695 & 2.577 & 7.201 & .723 \\
\hline 3 & 3.15 & 1.201 & -.139 & -.817 & .775 & 34 & 1.55 & .865 & 1.568 & 2.008 & .723 \\
\hline 4 & 3.62 & 1.092 & -.704 & -.112 & .782 & 36 & 1.58 & .863 & 1.446 & 1.521 & .765 \\
\hline 5 & 3.23 & 1.065 & -.204 & -.394 & .823 & \multicolumn{6}{|c|}{ Negativistic-Cognitive } \\
\hline 6 & 3.34 & 1.109 & -.319 & -.542 & .774 & 20 & 2.59 & .922 & -.140 & -.073 & .503 \\
\hline 7 & 3.90 & .970 & -1.035 & 1.032 & .687 & 26 & 2.28 & 1.011 & .003 & -1.032 & .445 \\
\hline \multicolumn{6}{|c|}{ Positivistic } & 33 & 2.73 & 1.141 & -.169 & -.971 & .497 \\
\hline 9 & 4.34 & .781 & -1.138 & 1.425 & .711 & 35 & 2.12 & 1.016 & .205 & -1.123 & .704 \\
\hline 11 & 4.32 & .817 & -1.147 & 1.211 & .732 & 37 & 1.93 & .965 & .473 & -.966 & .725 \\
\hline 12 & 4.00 & .936 & -.698 & .135 & .734 & 38 & 1.99 & .958 & .363 & -.990 & .739 \\
\hline 13 & 4.26 & .874 & -1.397 & 2.199 & .724 & 39 & 1.98 & .973 & .505 & -.717 & .667 \\
\hline 14 & 3.48 & .882 & .170 & .037 & .557 & \multicolumn{6}{|c|}{ Myths } \\
\hline 15 & 4.30 & .799 & -1.046 & .979 & .728 & 21 & 1.81 & 1.108 & 1.126 & .162 & .432 \\
\hline 16 & 3.62 & .958 & -.182 & -.203 & .685 & 23 & 1.38 & .752 & 2.002 & 3.428 & .705 \\
\hline 17 & 3.95 & .945 & -.494 & -.374 & .651 & 24 & 1.22 & .654 & 3.439 & 12.675 & .578 \\
\hline 18 & 3.43 & .889 & .268 & .039 & .628 & 27 & 1.22 & .612 & 3.173 & 10.887 & .628 \\
\hline \multicolumn{12}{|c|}{ Negativistic-Emotional } \\
\hline 28 & 2.53 & 1.434 & .337 & -1.285 & .597 & & & & & & \\
\hline 29 & 2.30 & 1.091 & .327 & -.774 & .551 & & & & & & \\
\hline 30 & 2.39 & 1.327 & .448 & -1.067 & .624 & & & & & & \\
\hline
\end{tabular}

The item-total correlation per factor produced a value of .27 for item 19, corresponding to the Negativistic-Cognitive factor (19. The activity of bats in farms affects sales of farm products), it was therefore eliminated from the questionnaire. The rest of the items presented an item-total correlation per factor higher than .38.

The inter-item correlation analysis produced low values (between .14 and .30) for two items of the Myths factor (22. Bats are sacred spiritual elements; 25. Bats bring good luck), except in the correlation between themselves (.52). This is because these two items measure positive myths while the rest measure negative myths, causing confusion in the dimension. Those who disagree with a mythological view of bats score low in all the items, but people who agree with this view do not give a uniform response: people who agree with positive myths tend to disagree with negative myths and vice-versa. For this reason, we decided to eliminate items 22 and 25. 
Finally, we studied the high correlations to detect possible multicollinearity and identify redundant items. Of the total, three pairs of items presented correlations higher than .8. Two items belonging to the Positivistic factor were eliminated, namely item 8 (Bats play an important role in the environment), which presented a correlation of .87 with item 9 (Bats are important for the functioning of our ecosystem); and item 10 (Conservation of bats is important) with correlation of .82 with item 9, and .83 with item 11 (Human beings should protect bats). Table 2 presents descriptions of the 34 items that were finally included in the instrument.

\subsection{Exploratory Factor Analysis}

The relation between the variables is high, we therefore considered that the quality of the data for applying EFA is good $(\mathrm{KMO}=0.943)$. The result of Bartlett's test indicate that the correlation matrix differs from the identity matrix, $\chi 2$ $(561)=16874.928$ with a significance level $p<.001$. The EFA produced a dimensional structure of 6 factors which explain $57.6 \%$ of the variance. This structure is consistent with the structure obtained in the pilot sample, except for item 39 (Bats are aggressive), which applies to the Negativistic-Cognitive dimension, instead of the NegativisticEmotional. Table 3 presents the factorial weights of the items in each of the dimensions.

\section{Table 3}

EFA results in sample group $1(N=819)$. Extraction of unweighted least squares and oblimin oblique rotation. 
Items

Factors

$\begin{array}{llllll}1 & 2 & 3 & 4 & 5 & 6\end{array}$

Scientistic

1 I would like to learn more about bats

$\begin{array}{llllll}.650 & -.030 & -.039 & .027 & -.051 & -.145\end{array}$

2 Knowing about the activity of bats is important for me

$\begin{array}{llllll}.739 & -.072 & .075 & -.121 & -.034 & -.055\end{array}$

3 I would like to take part in a trip or a congress, or other

$\begin{array}{llllll}.820 & -.001 & -.038 & -.021 & .009 & .107\end{array}$ activity, to learn about bats

4 It would be interesting to take part in a scientific activity about bats

$5 \quad$ I would like to exchange knowledge about bats with other people

6 It would be interesting to be able to teach others about bats

$\begin{array}{llllll}.818 & .020 & -.044 & .045 & .034 & .004\end{array}$

$\begin{array}{llllll}.875 & .014 & -.018 & -.017 & -.009 & .086\end{array}$

$\begin{array}{lllll}.829 & .004 & .019 & -.010 & -.010 \quad .083\end{array}$

$7 \quad$ I would like to read a scientific article or see a documentary about bats

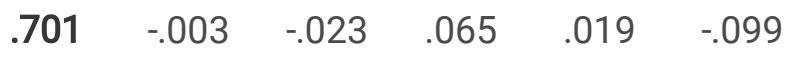

Positivistic

9 Bats are important for the functioning of our ecosystem $\quad \begin{array}{llllll}.055 & -.735 & .066 & .133 & .089 & -.154\end{array}$

11 Humans should protect bats $\quad \begin{array}{llllll}0.018 & -.712 & -.073 & .268 & .050 & .003\end{array}$

12 Spaces should be set aside for bat conservation in $\quad \begin{array}{lllllllll}0.084 & -.702 & -.047 & .084 & -.029 & .067\end{array}$ farmland

13 Humans must learn to coexist with bats

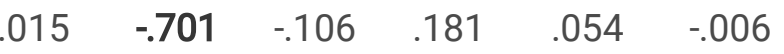

14 Bat excrement is a source of good fertiliser for farming $\quad \begin{array}{lllllll}.037 & -.528 & -.127 & -.085 & -.022 & .031\end{array}$

15 Bats help in the biological control of pests $\quad \begin{array}{llllll}0.013 & -.726 & .095 & .082 & -.027 & -.131\end{array}$

16 Bats help food security $\quad \begin{array}{llllll}0.154 & .001 & -.703 & .014 & -.184 & -.034\end{array}$

17 Some species of bat help to disperse tree seeds $\quad \begin{array}{lllllll}.062 & -.600 & -.021 & -.032 & -.056 & -.050\end{array}$

18 The activity of bats gives added value to crops in the $\quad \begin{array}{lllllll}.030 & -.645 & -.006 & -.206 & -.138 & .055\end{array}$ market

Negativistic-Emotional

\begin{tabular}{llllllll}
28 & Bats are ugly & -.120 & .021 & .708 & -.022 & -.103 & .046 \\
\hline 29 & Bats are dangerous for humans & .044 & .172 & .564 & -.032 & .180 & -.023 \\
\hline 30 & I am afraid of bats & -.064 & -.007 & .644 & -.036 & .053 & .076 \\
\hline Negativistic-Behavioural & & & & & \\
\hline $\mathbf{3 1}$ & Bats should be exterminated & .013 & .205 & .138 & -.572 & .111 & .142 \\
\hline 32 & We should attack bats & -.021 & .092 & .078 & -.526 & .138 & .307 \\
\hline 34 & $\begin{array}{l}\text { Bat refuges should be eliminated to prevent them from } \\
\text { breeding (block up caves, cut down trees, etc.) }\end{array}$ & -.067 & .031 & .153 & -.419 & .357 & .100
\end{tabular}




\begin{tabular}{|c|c|c|c|c|c|c|c|}
\hline 36 & We should stop bats from reproducing & -.044 & .122 & .026 & -.478 & .464 & .067 \\
\hline \multicolumn{8}{|c|}{ Negativistic-Cognitive } \\
\hline 20 & Bats' activity contaminates crops & -.045 & .164 & .092 & .142 & .386 & .073 \\
\hline 26 & Bats attract other species of rodents & .006 & -.008 & .024 & .056 & .405 & .207 \\
\hline 33 & Bats can be dangerous for domestic animals & .026 & .002 & .353 & .023 & .385 & -.079 \\
\hline 35 & Bats contaminate water resources & -.075 & .030 & .114 & -.057 & .669 & -.014 \\
\hline 37 & Bats damage machinery/buildings & -.060 & .037 & -.016 & -.112 & .741 & .034 \\
\hline 38 & Bats harm agriculture & -.040 & .218 & -.109 & -.094 & .749 & -.042 \\
\hline 39 & Bats are aggressive & -.019 & .051 & .250 & -.102 & .507 & .016 \\
\hline \multicolumn{8}{|c|}{ Myths } \\
\hline 21 & The bat is a symbol of ill omen & .053 & .105 & .212 & .030 & .086 & .373 \\
\hline 23 & $\begin{array}{l}\text { When you see a bat, it is a sign that someone wants to } \\
\text { harm you }\end{array}$ & .029 & .002 & .086 & .113 & .051 & .820 \\
\hline 24 & Bats become vampires & .004 & .046 & -.062 & -.069 & -.046 & .727 \\
\hline 27 & Bats should be burnt to prevent witchcraft & -.093 & -.040 & -.013 & -.180 & .035 & .738 \\
\hline
\end{tabular}

\subsection{Confirmatory Factor Analysis}

Here we try to corroborate the fit of the 6-factor model resulting from the EFA by CFA with the Group 2 sample $(\mathrm{N}=819)$. All the models present an adequate fit (Table 4), except the Bifactor model which presents an optimum fit. Nevertheless, the OmegaH value is .24, so the total scores cannot be considered essentially one-dimensional. Besides, although PUC produces a value of .834 , the ECV is equal to .14. These values indicate that considering the instrument as essentially one-dimensional involves a very high relative bias. The Bifactor model was discarded, and with it the possibility of considering a global score for the instrument. The oblique and hierarchical-oblique models were preferred for their better fit compared to second and third order hierarchical models. Of these two, although the oblique model is more parsimonious, we preferred the hierarchical-oblique model for its greater theoretical coherence. Figure 2 presents the factorial weights of the items in the different factors.

The correlations between the factors are significant. These correlations are negative, except between the pairs Scientistic and Positivistic, and Negativistic and Myths. The correlation between the Negativistic and Positivistic factors is higher than .8, which raises a suspicion of multicollinearity. Nevertheless, the level of tolerance between the two scores is .546, and the VIF is 1.83 , so this suspicion can be discarded.

\section{Table 4}

Fit indices of models subjected to CFA 


\begin{tabular}{|llllll|}
\hline Models & X2 & df & CFI & RMSEA & TLI \\
\hline Oblique (M1) & 1603,3 & 512 & .939 & $.051(0,048-0,054)$ & 0.933 \\
\hline Second-order hierarchical (M2) & 1917.17 & 521 & .922 & $.057(0,054-0,060)$ & 0.916 \\
\hline Hierarchical-oblique (M3) & 1642,3 & 518 & .937 & $.051(0,049-0,054)$ & 0.932 \\
\hline Third order hierarchical (M4) & 1927 & 520 & .921 & $.057(0,055-0,060)$ & 0.915 \\
\hline Bifactor (M5) & 1177,7 & 484 & .961 & $.042(0,039-0,045)$ & 0.955 \\
\hline
\end{tabular}

\section{Table 5}

Correlation between factors of BAtSS

\begin{tabular}{|llll|}
\hline & Positivistic & Negativistic & Myths \\
\hline Scientifistic & .573 & -.461 & -.280 \\
\hline Positivistic & & -.816 & -.500 \\
\hline Negativistic & & & .765 \\
\hline
\end{tabular}

Note: All correlations are significant $p<.000$

\subsection{Internal consistency}

McDonald's Omega and the Ordinal Alpha coefficient indicate that the instrument presents adequate internal consistency for the four factors and the three facets (see Table 6).

\section{Table 6}

Omega McDonal's coefficient and Ordinal Alpha for factors and facets.

\begin{tabular}{|lllllllll|}
\hline \multirow{3}{*}{ Omega McDonal's } & & $\mathrm{S}$ & $\mathrm{P}$ & $\mathrm{N}$ & $\mathrm{NE}$ & $\mathrm{NB}$ & $\mathrm{NC}$ & $\mathrm{M}$ \\
\cline { 2 - 9 } & Group 1 $(\mathrm{N}=820)$ & .938 & .936 & .940 & .812 & .943 & .888 & .907 \\
\cline { 2 - 9 } Ordinal Alpha & Group 2 $(\mathrm{N}=819)$ & .920 & .895 & .932 & .784 & .947 & .871 & .876 \\
& Group 1 $(\mathrm{N}=820)$ & .937 & .936 & .939 & .810 & .942 & .882 & .900 \\
\cline { 2 - 9 } & Group 2 $(\mathrm{N}=819)$ & .919 & .893 & .950 & .775 & .945 & .867 & .869 \\
\cline { 2 - 8 }
\end{tabular}

Note: GF = General Factor; $\mathrm{S}=$ Scientifistic; $\mathrm{P}=$ Positivistic; $\mathrm{N}=$ Negativistic; NE = Negativistic-Emotional; NB = Negativistic-Behavioural; NC = Negativistic-Cognitive; $\mathrm{M}=$ Myths

\subsection{Discriminative Capacity and Difficulty of the items}


Table 7 presents the results of the Samejima Graduated Response Model. Considering the factors and facets representing negative evaluations of bats, we find that the items where change is most difficult are: 29 in Negativistic-Emotional; 34 and 36 in Negativistic-Behavioural; and 20, 26 and 36 in Negativistic-Cognitive. In the Myths dimension, the items that represent the ideas that are most difficult to modify in the sample are 21 and 23.

\section{Table 7}

Discrimination (a) and difficulty (b) parameters of the IRT. 


\begin{tabular}{|c|c|c|c|c|c|c|c|}
\hline Factor/Facet & items & a & $\mathrm{b}_{1}$ & $\mathrm{~b}_{2}$ & $b_{3}$ & $\mathrm{~b}_{4}$ & $b_{4}-b_{1}$ \\
\hline \multirow[t]{7}{*}{ Scientifistic } & 1 & 2.37 & -2.98 & -2.51 & -0.89 & 0.59 & 3,57 \\
\hline & 2 & 1.94 & -2.39 & -1.12 & 0.31 & 1.60 & 3,99 \\
\hline & 3 & 3.35 & -1.51 & -0.68 & 0.18 & 1.04 & 2,55 \\
\hline & 4 & 3.69 & -1.86 & -1.13 & -0.42 & 0.75 & 2,61 \\
\hline & 5 & 3.47 & -1.75 & -0.91 & 0.15 & 1.31 & 3,06 \\
\hline & 6 & 2.72 & -1.91 & -0.99 & 0.01 & 1.17 & 3,08 \\
\hline & 7 & 2.19 & -2.49 & -1.75 & -0.86 & 0.72 & 3,21 \\
\hline \multirow[t]{9}{*}{ Positivistic } & 9 & 2,64 & $-3,23$ & $-2,90$ & $-1,16$ & 0,11 & 3,34 \\
\hline & 11 & 3,05 & $-3,13$ & $-2,39$ & $-1,04$ & 0,08 & 3,21 \\
\hline & 12 & 2,44 & $-2,92$ & $-2,08$ & $-0,62$ & 0,51 & 3,43 \\
\hline & 13 & 2,44 & $-2,82$ & $-2,01$ & $-1,1$ & 0,22 & 3,04 \\
\hline & 14 & 1,36 & $-3,86$ & $-2,52$ & 0,45 & 1,66 & 5,52 \\
\hline & 15 & 2,42 & $-3,85$ & $-2,8$ & $-1,06$ & 0,20 & 4,05 \\
\hline & 16 & 1,86 & $-3,17$ & $-1,98$ & 0,13 & 1,27 & 4,44 \\
\hline & 17 & 1,79 & $-3,64$ & $-2,64$ & $-0,49$ & 0,67 & 4,31 \\
\hline & 18 & 1,51 & $-3,45$ & $-2,07$ & 0,66 & 1,67 & 5,12 \\
\hline \multirow[t]{3}{*}{ Negativistic-Emotional } & 28 & 2,02 & $-0,49$ & 0,09 & 0,78 & 1,77 & 2,26 \\
\hline & 29 & 1,55 & $-0,98$ & 0,04 & 1,70 & 3,32 & 4,30 \\
\hline & 30 & 3,17 & $-0,46$ & 0,09 & 0,74 & 1,68 & 2,14 \\
\hline \multirow[t]{4}{*}{ Negativistic-Behavioural } & 31 & 6,06 & 0,72 & 1,37 & 2,07 & 2,32 & 1,60 \\
\hline & 32 & 5,46 & 0,81 & 1,45 & 2,25 & 2,49 & 1,68 \\
\hline & 34 & 3,31 & 0,50 & 1,32 & 2,19 & 2,68 & 2,18 \\
\hline & 36 & 3,38 & 0,29 & 1,16 & 2,06 & 2,61 & 2,32 \\
\hline \multirow[t]{7}{*}{ Negativistic-Cognitive } & 20 & 1,69 & $-1,73$ & $-0,47$ & 1,78 & 3,46 & 5,19 \\
\hline & 26 & 1,12 & $-1,20$ & $-0,25$ & 2,73 & 5,40 & 6,60 \\
\hline & 33 & 1,41 & $-1,48$ & $-0,53$ & 0,99 & 2,97 & 4,45 \\
\hline & 35 & 2,75 & $-0,56$ & 0,00 & 1,81 & 2,63 & 3,19 \\
\hline & 37 & 2,74 & $-0,23$ & 0,38 & 2,1 & 2,77 & 3,00 \\
\hline & 38 & 3,38 & $-0,44$ & 0,23 & 1,81 & 2,92 & 3,36 \\
\hline & 39 & 2,35 & $-0,53$ & 0,32 & 1,87 & 2,81 & 3,34 \\
\hline Myths & 21 & 1,54 & 0,20 & 0,93 & 1,84 & 3,03 & 2,83 \\
\hline
\end{tabular}




\begin{tabular}{|lllllll|}
23 & 3,65 & 0,68 & 1,23 & 2,38 & 2,95 & 2,27 \\
\hline 24 & 3,55 & 1,23 & 1,69 & 2,35 & 2,61 & 1,38 \\
\hline 27 & 4,16 & 1,17 & 1,60 & 2,48 & 2,64 & 1,47 \\
\hline
\end{tabular}

\subsection{Concurrent validity}

Males present a higher mean score in the Positivistic factor, and females in the Negativistic factor and its facets. In both the size of the effect is small. Statistically significant differences are found for the Scientistic and Myths factors, but the Hedges' g statistic indicates that these have a zero effect (see Table 8).

Statistically significant differences are found in level of education with a small size of effect in the Positivistic dimension, and an intermediate effect in the Scientistic dimension and the Negativistic-Cognitive facet. The other significant differences present a nil size of effect (see Table 9). In the Scientistic dimension, the participants with postgraduate education (high level) present a lower mean score than participants with university or professional/technical education ( $p<.000$; medium level), and with primary or secondary education $(p<.000$; low level). The latter present lower mean scores in the Positivistic dimension than medium $(p=.046)$ and high level participants $(p=.001)$. Finally, the high level participants have a lower mean score in the Negativistic-Cognitive facet than medium $(p=005)$ and low level participants $(p<.000)$; while participants with a medium level of education have a lower mean score than those with low level of education $(p=.016)$.

\section{Table 8}

Difference of means between males and females in the factors of BAtSS

\begin{tabular}{|lllllll|}
\hline & Male $(\mathrm{n}=747) \mathrm{MD}(\mathrm{SD})$ & Female $(\mathrm{n}=887) \mathrm{MD}(\mathrm{SD})$ & $\mathrm{T}$ & $\mathrm{df}$ & $\mathrm{p}$ & $\mathrm{g}$ \\
\hline Scientifistic & $25,44(5.80)$ & $24,73(5.68)$ & 2.490 & 1632 & .013 & -.12 \\
\hline Positivistic & $36.25(5.50)$ & $34.25(5.48)$ & 7.354 & 1632 & $<.000$ & -.36 \\
\hline Negativistic & $27.50(8.49)$ & $31.05(9.16)$ & -8.057 & 1632 & $<.000$ & .40 \\
\hline Negativistic-Emotional & $6.76(2,79)$ & $7.75(3.15)$ & -6.751 & 1632 & $<.000$ & .33 \\
\hline Negativistic-Behavioural & $5.44(2.49)$ & $6.08(2.73)$ & -4.936 & 1632 & $<.000$ & .24 \\
\hline Negativistic-Cognitive & $15.29(4.81)$ & $17.20(4.77)$ & -8.036 & 1632 & $<.000$ & .39 \\
\hline Myths & $5.56(2.39)$ & $5.94(2.48)$ & $-3,093$ & 1632 & .002 & .15 \\
\hline
\end{tabular}

\section{Table 9}

Differences of means in the factors and facets of the BAtSS, according to educational level. 


\begin{tabular}{|c|c|c|c|c|c|c|}
\hline & \multicolumn{6}{|c|}{ Educational level } \\
\hline & $\begin{array}{l}\text { Undergraduate } \\
(\mathrm{n}=863)\end{array}$ & $\begin{array}{l}\text { University or } \\
\text { professional } \\
\text { technician }\end{array}$ & $\begin{array}{l}\text { Postgraduate } \\
(n=244)\end{array}$ & $F$ & $d$ & $\begin{array}{l}\text { Post-hoc } \\
\text { (Scheffe) }\end{array}$ \\
\hline & & $(n=532)$ & & & & \\
\hline & MD (SD) & $\mathrm{MD}(\mathrm{SD})$ & $\mathrm{MD}(\mathrm{SD})$ & & & \\
\hline Scientifistic & $25.57(5.44)$ & $25.06(5.67)$ & $23.22(6.55)$ & $16.270^{\star \star \star}$ & .41 & $3<1,2$ \\
\hline Positivistic & $34.70(5.16)$ & $35.46(5.74)$ & $36.19(6.43)$ & $7.912^{\star \star \star}$ & .27 & $1<1,3$ \\
\hline Negativistic & $29.88(8.53)$ & $29.40(9.57)$ & $27.85(9.33)$ & $4.820^{\star *}$ & .09 & $3<1$ \\
\hline $\begin{array}{l}\text { Negativistic- } \\
\text { Emotional }\end{array}$ & $7.28(2.86)$ & 7.31 (3.21) & $7.31(3.23)$ & 0.017 & & \\
\hline $\begin{array}{l}\text { Negativistic- } \\
\text { Behavioural }\end{array}$ & $5.71(2.50)$ & $5.97(2.83)$ & $5.64(2.72)$ & 1.977 & & \\
\hline $\begin{array}{l}\text { Negativistic- } \\
\text { Cognitive }\end{array}$ & $16.88(4.62)$ & $16.11(5.04)$ & $14.89(5.10)$ & $16.828^{\star \star *}$ & .41 & $\begin{array}{l}3<1,2 \\
2<1\end{array}$ \\
\hline Myths & $5.82(2.40)$ & $5.91(2.66)$ & $5.33(2.18)$ & $4.837^{\star \star *}$ & .12 & $3<1,2$ \\
\hline
\end{tabular}

$*<.05, * *<.01, * * *<.001$

\section{Discussion}

Considering the importance of attitudes in the development of conservation behaviours, and based on the contribution of previous measurement systems, we developed Bats Attitudes Standard Scale (BAtSS) in a Chilean community sample to evaluate attitudes towards bats. After studying the content validity and initial analysis in a pilot sample, we analysed items and the factorial structure of the scale by a crossed validity strategy. We examined the concurrent validity and the internal consistency. Furthermore, we identified the attitudes which are most difficult to change.

After analysis of the items, we obtained a scale of 34 Likert-type reagents with discriminative capacity, organised in an oblique-hierarchical factorial structure with good values of internal consistency. BAtSS presents 4 correlated factors. Two of them represent a positive evaluation of bats (Scientistic and Positivistic), and the other two a negative evaluation (Negativistic and Myths). The Negativistic dimension is hierarchical, as it sub-divides into three facets (Negativistic-Emotional, Negativistic-Behavioural, Negativistic-Cognitive). This theoretical model differs from others in the literature, apart from the Scientistic dimension which maintains high levels of coherence with earlier works (Barnes, 2013; Musila et al., 2018; Prokop et al., 2009; Prokop \& Tunnicliffe, 2008).

The Positivistic dimension is composed of items referring to concern for conservation of bat species from an ecologistic perspective; these are common items in other scales under the headings of the Ecologistic dimension (Musila et al., 2018; Prokop et al., 2009) or the Eco-scientistic dimension (Barnes, 2013; Prokop \& Tunnicliffe, 2008). It also considers positive evaluation of bat species based on their importance in ecosystem functioning and farming. This is an innovative contribution based on the Utilitarian typology of Kellert $(1980,1984)$, which makes it possible to capture results obtained in other works investigating the relation between positive attitudes and recognition of the benefits of bats for the ecosystem (Castilla et al., 2020). Nevertheless, IRT analyses indicate that the items on 
ecologistic attitudes have greater capacity to discriminate the score of each participant in the factor, and that the ideas covered by the rest of the items are more difficult to change.

The Negativistic dimension is present in the theoretical models of all the instruments reported in the literature (Barnes, 2013; Musila et al., 2018; Prokop et al., 2009; Prokop \& Tunnicliffe, 2008); in the BAtSS, however, this dimension has a hierarchical structure which enriches the measurement. Individuals are classified differentially into emotional, behavioural and cognitive negative attitudes, allowing different negativistic profiles to be identified based on the combinations of the scores in the three sub-scales. This is a particularly important contribution in the field of conservation, since these attitudes are related with aggressive behaviour, support for population control strategies and the killing of bats (Fagan et al., 2018; Reid, 2016; Shapiro et al., 2020; Tanalgo et al., 2016). Detailed knowledge of negativistic individuals can help in the development of more relevant prevention and intervention strategies. $A$ trend is likewise observed in the results of the IRT analyses: the ideas which are most difficult to change are those which identify a more immediate danger to humans. Fortunately, the most extreme negative behaviours are the easiest to change.

Finally, researchers have had varying success in capturing attitudes to mythology. This dimension was incorporated into the BAQ of Prokop et al. (2009), although it did not achieve adequate levels of internal consistency. Musila et al.'s version of the same instrument (2018) obtained acceptable levels in this dimension, while Barnes (2013) and Prokop and Tunnicliffe (2008) evaluated myths about bats as an independent measurement, not as part of the measurement of attitudes. This persistent interest of investigators in the mythological view, despite the difficulties, is rooted in its relation with negativistic attitudes and the complexity of changing attitudes when they are based on mythological beliefs (Barnes, 2013; de Prada \& Barragán-Tabares, 2018; Prokop \& Tunnicliffe, 2008; Suwannarong et al., 2020). Myths and folk stories have led to people lighting fires in bats' caves, killing them, and even capturing them to use in supposed cures for diseases (Kamins et al., 2015; Rego et al., 2015). Fortunately, in the BAtSS scale we obtained a Myths dimension with a good level of internal consistency (Martínez-Arias et al., 2014). Nevertheless, its cultural nature complicates extrapolation to other contexts, so special attention will be needed in use with other populations.

As evidence of concurrent validity, we found differences in attitudes by gender and level of education. This shows that the scale has discriminative capacity between groups (International Test Commission, 2017; Martínez-Arias et al., 2014; Muñiz \& Fonseca-Pedrero, 2019). These results agree in part with the scientific evidence, although this comparison is subject to limitations due to the disparity of theoretical models, measurements and cultural contexts between studies. Musila et al, (2018), Prokop \& Tunnicliffe (2008) and Prokop et al. (2009) found that women had higher scores in negative and mythological attitudes, although it is men who carry out aggressive actions against bats in most cases (Musila et al., 2018). (Barnes, 2013) found no differences by gender in his study sample. The literature indicates that greater knowledge of biology and/or bats, and higher level of education, support a more positive and less mythological evaluation (Barnes, 2013; Castilla et al., 2020; Musila et al., 2018; Prokop et al., 2009; Prokop \& Tunnicliffe, 2008; Shapiro et al., 2020).

In our study sample, the Myths dimension showed no difference by gender and level of education, which may indicate that the mythological view is less firmly rooted in Chilean culture. It turns out that the most extreme ideas are the easiest to modify (items 24 and 27). Females have a more negative attitude than males on the emotional, cognitive and behavioural levels, but in the case of level of education, the only negative attitudes that establish differences are cognitive: the lower the level of education, the stronger is the negative cognitive attitude. This is an interesting finding, since it is more difficult to change emotional and behavioural attitudes (Briñol et al., 2007). Finally, we observed a similar tendency in the rest of the results, except that scientific interest in bats is lower among 
participants with postgraduate studies. We interpret this finding as the result of more strongly developed and defined scientific interests in individuals of this group whose studies are unrelated with bats.

We identified the lack of representativeness of the sample as a limitation of this work. Furthermore, the cultural nature of the Myths dimension would hinder the adaptation and validation of BAtSS in other cultural contexts than Chile. We also think that we need to continue accumulating evidence of validity in Chile, to increase the solidity of the scale. For example, in future work the BAtSS scale should be studied to confirm definitively its internal structure, as well as analysing the convergent validity of the scale based on other theoretical constructs, for example knowledge about bats.

\section{Conclusions}

The current situation in which bats are persecuted generally around the world requires an effort by investigators to address the human-bat conflict to favour the development of conservation policies. People's attitudes towards these animals have proved to be of key importance in this process. We identified the need to construct a tool that investigators can use to measure this theoretical construct in a specific cultural context, but which is potentially adaptable to other sociocultural scenarios (Martínez-Arias et al., 2014).

In this study we designed the BAtSS. This scale, and the theoretical model on which it is based, provide a tool with proven validity and reliability for measuring attitudes towards bats in Chilean community population. Its adequate psychometric properties make it a good candidate for adaptation to other cultural contexts. Extension of its use would facilitate the replication, scientific gold standard for the confirmation of results (Milfont \& Klein, 2018). This framework pushes forward practical understandings of conservation conflict interventions by offering a novel, transdisciplinary, diagnostic tool for better understanding their complex, multifaceted variables (Harrison \& Loring, 2020).

\section{Declarations}

\section{Author contributions}

$B P, A B$ and $F L$ designed the study. BP, $A B$ and FL collected data. BP, BA and $A B$ analysed the data and prepared the figures and tables. $B P, B A, A B$ and $F L$ writing and editing the text. $B P, A B$ and $F L$ supervised the project through all its phases.

\section{Conflicts of interest}

None

\section{Ethical standards}

Free, prior and informed consent was sought before the survey.

\section{Acknowledgments}

We thank Ángeles Haz for its help and Juan Carlos Imio for its help in the collected data. AB, and FL were funded by the projects “Estudio para el apoyo al manejo productivo mediante el control biológico de plagas a través de murciélagos insectívoros para una agricultura más sostenible y adaptada al Cambio Climático en el Centro-Sur de 
Chile (PYT-2017-0188)" of Fundación para la Innovación Agraria (FIA). FL was supported partially by FONDECYT No 11180514.

\section{Competing Interests}

The authors declare no competing interests.

\section{References}

Aziz, S. A., Clements, G. R., Giam, X., Forget, P.-M., \& Campos-Arceiz, A. (2017). Coexistence and conflict between the island flying fox (Pteropus hypomelanus) and humans on Tioman Island, Peninsular Malaysia. Human Ecology, 45(3), 377-389. https://doi.org/10.1007/s10745-017-9905-6

Barnes, P. (2013). An assessment of human attitude and behaviour towards the critically endangered Pteropus rodricensis [PhD Thesis]. Imperial College London.

Bhattacharjee, J., Dutta, B. K., Bhattacharjee, P. C., Singha, H., Deb, P., Dutta, H., \& Hussain, M. M. (2018). Student perceptions of, and attitudes toward, bats in Barak valley, Assam, India. Anthrozoös, 31(4), 411-422.

https://doi.org/10.1080/08927936.2018.1482113

Briñol, P., Fakces, C., \& Becerra, A. (2007). Actitudes. In Psicología social(J.F. Morales, E. Gaviria, M.C. Moya, M.I. Cuadrado, pp. 457-490). McGraw-Hill.

Castilla, M. C., Campos, C., Colantonio, S., \& Díaz, M. (2020). Perceptions and attitudes of the local people towards bats in the surroundings of the Escaba dam (Tucumán, Argentina). Ethnobiology and Conservation.

https://doi.org/10.15451/ec2020-03-9.09-1-14

de Prada, S. S., \& Barragán-Tabares, L. M. (2018). Relatos y percepciones sobre murciélagos por parte de la comunidad Tocagón en Otavalo, Ecuador. Ethnoscientia, 3. https://doi.org/10.22276/ethnoscientia.v3i0.141

Fagan, K. E., Willcox, E. V., \& Willcox, A. S. (2018). Public attitudes toward the presence and management of bats roosting in buildings in Great Smoky Mountains National Park, Southeastern United States. Biological Conservation, 220, 132-139. https://doi.org/10.1016/j.biocon.2018.02.004

Fagerland, M. W. (2012). t-tests, non-parametric tests, and large studies-a paradox of statistical practice? BMC Medical Research Methodology, 12(1), 78. https://doi.org/10.1186/1471-2288-12-78

Gbogbo, F., \& Kyei, M. O. (2017). Knowledge, perceptions and attitude of a community living around a colony of straw-coloured fruit bats (Eidolon helvum) in Ghana after Ebola virus disease outbreak in West Africa. Zoonoses and Public Health, 64(8), 628-635. https://doi.org/10.1111/zph.12357

Harrison, H. L., \& Loring, P. A. (2020). Seeing beneath disputes: A transdisciplinary framework for diagnosing complex conservation conflicts. Biological Conservation, 248, 108670.

Hefetz, A., \& Liberman, G. (2017). The factor analysis procedure for exploration: a short guide with examples / El análisis factorial exploratorio: una guía breve con ejemplos. Cultura y Educación, 29(3), 526-562.

https://doi.org/10.1080/11356405.2017.1365425

International Test Commission. (2017). The ITC guidelines for translating and adapting tests.

Page 20/24 
Kamins, A. O., Rowcliffe, J. M., Ntiamoa-Baidu, Y., Cunningham, A. A., Wood, J. L. N., \& Restif, O. (2015).

Characteristics and risk perceptions of ghanaians potentially exposed to bat-borne zoonoses through bushmeat. EcoHealth, 12(1), 104-120. https://doi.org/10.1007/s10393-014-0977-0

Kellert, S. R. (1980). Public attitudes toward critical wildlife and natural habitat issues. Phase 1. Government Reports, Announcements and Index, National Technical Information Service (NTIS), US Department of Commerce, 80(9).

Kellert, S. R. (1984). American attitudes toward and knowledge of animals: An update. In Advances in animal welfare science 1984/85 (pp. 177-213). The Humane Society of the United States.

Kellert, S. R. (1976). Perceptions of animals in American society. Transactions of the North American Wildlife and Natural Resources Conference, 41, 533-546.

Kingston, T. (2016). Cute, Creepy, or Crispy-How values, attitudes, and norms shape human behavior toward bats. In C. C. Voigt \& T. Kingston (Eds.), Bats in the Anthropocene: Conservation of Bats in a Changing World (pp. 571-595). Springer International Publishing. https://doi.org/10.1007/978-3-319-25220-9_18

Kline, R. B. (2016). Principles and practice of structural equation modeling (Fourth edition). The Guilford Press.

Knight, A. J. (2008). "Bats, snakes and spiders, Oh my!" How aesthetic and negativistic attitudes, and other concepts predict support for species protection. Journal of Environmental Psychology, 28(1), 94-103.

https://doi.org/10.1016/j.jenvp.2007.10.001

Kross, S. M., Ingram, K. P., Long, R. F., \& Niles, M. T. (2018). Farmer perceptions and behaviors related to wildlife and on-farm conservation actions. Conservation Letters, 11(1), e12364. https://doi.org/10.1111/conl.12364

Kunz, T. H., Braun de Torrez, E., Bauer, D., Lobova, T., \& Fleming, T. H. (2011). Ecosystem services provided by bats. Annals of the New York Academy of Sciences, 1223(1), 1-38. https://doi.org/10.1111/j.1749-6632.2011.06004.x

Lim, V.-C., \& Wilson, J.-J. (2019). Public perceptions and knowledge of, and responses to, bats in urban areas in peninsular Malaysia. Anthrozoös, 32(6), 825-834. https://doi.org/10.1080/08927936.2019.1673063

López-Baucells, A., Rocha, R., \& Fernández-Llamazares, Á. (2018). When bats go viral: negative framings in virological research imperil bat conservation. Mammal Review, 48(1), 62-66. https://doi.org/10.1111/mam.12110

Mahmood-ul-Hassan, M., Faiz-ur-Rehman, \& Salim, M. (2011). Public perceptions about the fruit bats in two horticulturally important districts of Pakistan. JAPS, Journal of Animal and Plant Sciences, 21(2), 135-141. CABDirect.

Martínez-Arias, R., Hernández-Lloreda, M. J., \& Hernández-Lloreda, M. V. (2014). Psicometría. Madrid: Alianza Editorial.

Milfont, T. L., \& Klein, R. A. (2018). Replication and reproducibility in cross-cultural psychology. Journal of CrossCultural Psychology, 49(5), 735-750. https://doi.org/10.1177/0022022117744892

Moran, D., Juliao, P., Alvarez, D., Lindblade, K. A., Ellison, J. A., Gilbert, A. T., Petersen, B., Rupprecht, C., \& Recuenco, S. (2015). Knowledge, attitudes and practices regarding rabies and exposure to bats in two rural communities in Guatemala. BMC Research Notes, 8(1), 955. https://doi.org/10.1186/s13104-014-0955-1

Page $21 / 24$ 
Muñiz, J., \& Fonseca-Pedrero, E. (2019). Diez pasos para la construcción de un test. C.O.P. Del Ppdo. de Asturias, 31.1, 7-16. https://doi.org/10.7334/psicothema2018.291

Musila, S., Prokop, P., \& Gichuki, N. (2018). Knowledge and perceptions of, and attitudes to, bats by people living around Arabuko-Sokoke Forest, Malindi-Kenya. Anthrozoös, 31(2), 247-262.

https://doi.org/10.1080/08927936.2018.1434065

Prokop, P., Fančovičová, J., \& Kubiatko, M. (2009). Vampires are still alive: Slovakian students' attitudes toward bats. Anthrozoös, 22(1), 19-30. https://doi.org/10.2752/175303708X390446

Prokop, P., \& Tunnicliffe, S. D. (2008). "Disgusting” animals: Primary school children's attitudes and myths of bats and spiders. EURASIA Journal of Mathematics, Science and Technology Education, 4(2).

https://doi.org/10.12973/ejmste/75309

Rego, K. M. da C., Zeppelini, C. G., Lopez, L. C. S., \& Alves, R. R. N. (2015). Assessing human-bat interactions around a protected area in northeastern Brazil. Journal of Ethnobiology and Ethnomedicine, 11(1), 80.

https://doi.org/10.1186/s13002-015-0058-7

Reid, J. L. (2016). Knowledge and experience predict indiscriminate bat-killing intentions among Costa Rican men. Biotropica, 48(3), 394-404. https://doi.org/10.1111/btp.12279

Reise, S. P. (2012). The Rediscovery of Bifactor Measurement Models. Multivariate Behavioral Research, 47(5), 667696. https://doi.org/10.1080/00273171.2012.715555

Reise, S. P., Bonifay, W. E., \& Haviland, M. G. (2013). Scoring and Modeling Psychological Measures in the Presence of Multidimensionality. Journal of Personality Assessment, 95(2), 129-140.

https://doi.org/10.1080/00223891.2012.725437

Rodriguez, A., Reise, S. P., \& Haviland, M. G. (2016). Applying bifactor statistical indices in the evaluation of psychological measures. Journal of Personality Assessment, 98(3), 223-237.

https://doi.org/10.1080/00223891.2015.1089249

Samejima, F. (1968). Estimation of latent ability using a response pattern of graded scored. ETS Research Bulletin Series, 1968(1), i-169. https://doi.org/10.1002/j.2333-8504.1968.tb00153.x

Sánchez-Oliva, D., Morin, A. J. S., Teixeira, P. J., Carraça, E. V., Palmeira, A. L., \& Silva, M. N. (2017). A bifactor exploratory structural equation modeling representation of the structure of the basic psychological needs at work scale. Journal of Vocational Behavior, 98, 173-187. https://doi.org/10.1016/j.jvb.2016.12.001

Santos, N. de J., Paz, E. S. da, Carneiro, I. de O., \& Franke, C. R. (2019). Evaluation of bat-related knowledge, perceptions, and practices in an urban community: A strategy for Conservation Biology and health promotion. Brazilian Journal of Biological Sciences, 6(13), 347-358. https://doi.org/10.21472/bjbs.061303

Shapiro, H. G., Wilcox, A. S., Tate, M., \& Willcox, E. V. (2020). Can farmers and bats co-exist? Farmer attitudes, knowledge, and experiences with bats in Belize. Human-Wildlife Interactions, 14. https://doi.org/10.26077/5WWPSP53

Smith, T. W. (2005). The laws of studying societal change. National Opinion Research Center. 
Suwannarong, K., Balthip, K., Kanthawee, P., Suwannarong, K., Khiewkhern, S., Lantican, C., Ponlap, T., Bupha, N., \& Amonsin, A. (2020). Bats and belief: A sequential qualitative study in Thailand. Heliyon, 6(6), e04208.

https://doi.org/10.1016/j.heliyon.2020.e04208

Tanalgo, K. C., Teves, R. D., Salvaña, F. R. P., Baleva, R. E., \& Tabora, J. A. G. (2016). Local community perception towards bats (Mammalia: Chiroptera) in Caves in South central Mindanao, Philippines: Threats and Implication for conservation. Wildlife Biology in Practice, 12(1), 381. https://doi.org/10.2461/wbp.2016.12.2

Upham, N. S., Esselstyn, J. A., \& Jetz, W. (2019). Inferring the mammal tree: Species-level sets of phylogenies for questions in ecology, evolution, and conservation. PLOS Biology, 17(12), e3000494.

https://doi.org/10.1371/journal.pbio.3000494

\section{Figures}
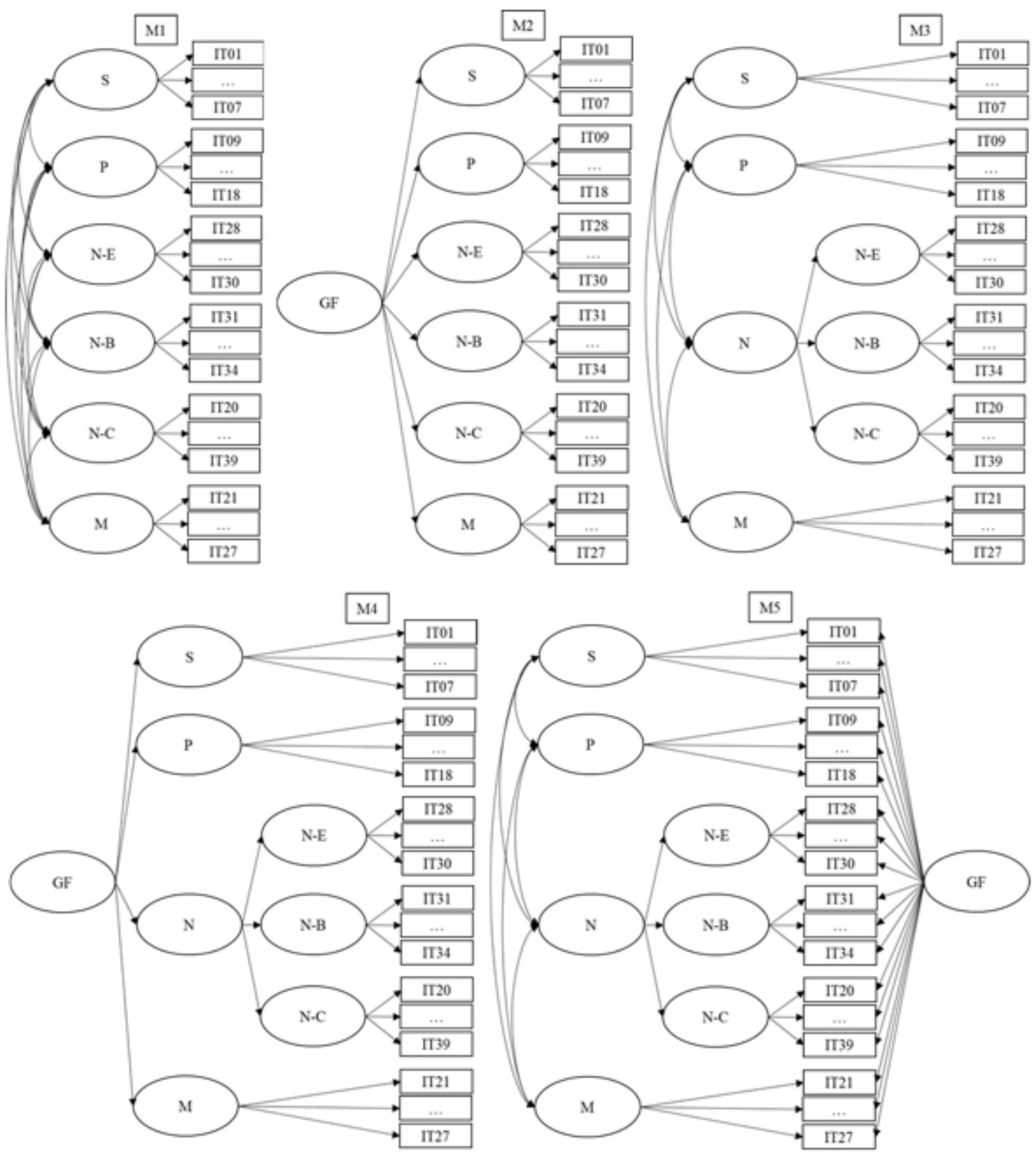

Figure 1 
Factorial models subjected to CFA Note: GF = General Factor; $\mathrm{S}=$ Scientifistic; $\mathrm{P}=$ Positivistic; $\mathrm{N}=$ Negativistic; $\mathrm{NE}=$ Negativistic-Emotional; NB = Negativistic-Behavioural; NC = Negativistic-Cognitive; $\mathrm{M}=$ Myths

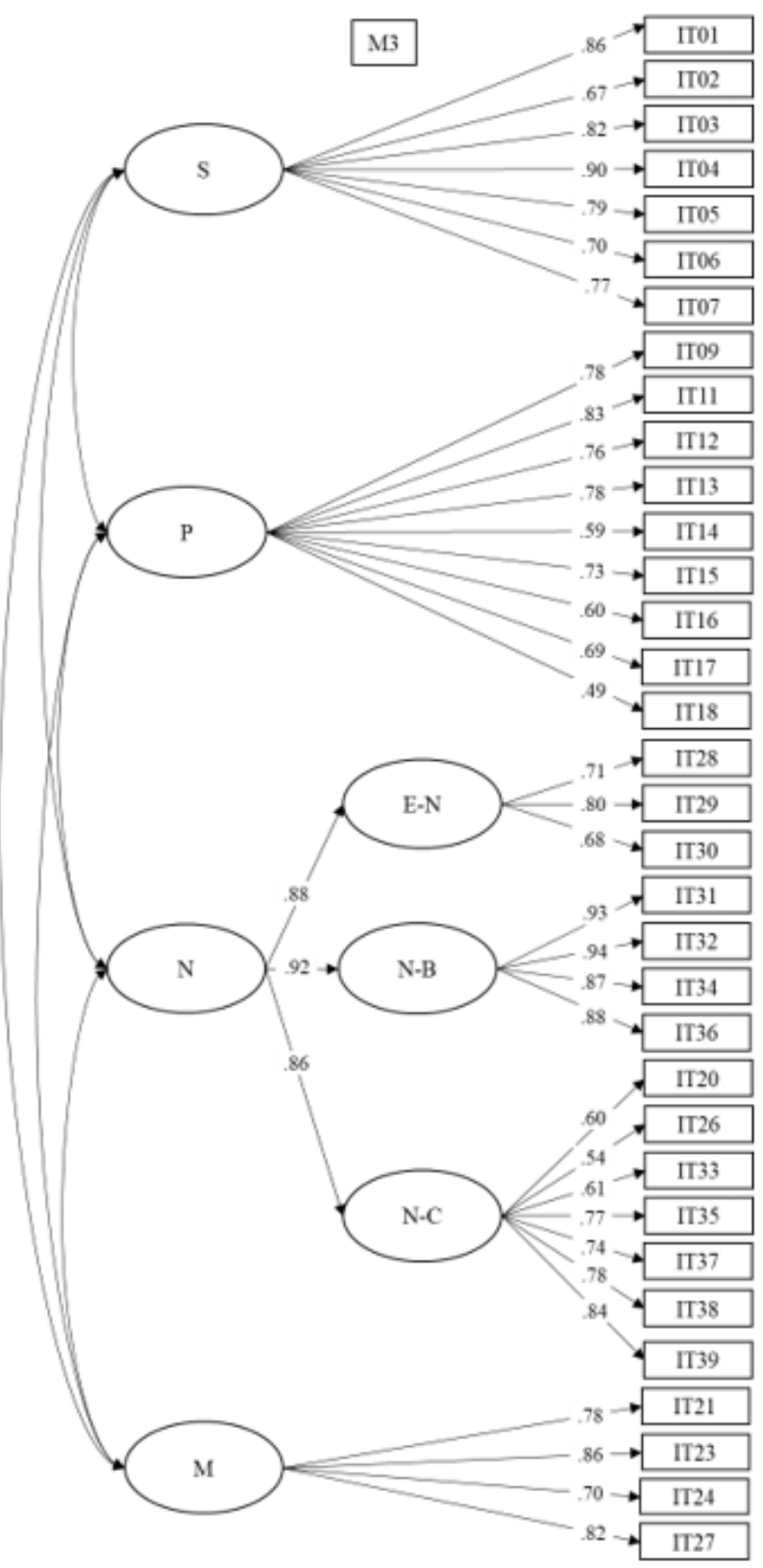

\section{Figure 2}

Factorial weights of the items in the hierarchical-oblique model (M3) Note: GF = General Factor; $\mathrm{S}=\mathrm{Scientifistic} ; \mathrm{P}=$ Positivistic; N = Negativistic; NE = Negativistic-Emotional; NB = Negativistic-Behavioural; NC = Negativistic-Cognitive; $M=$ Myths 